\title{
0 bebê interroga a sociologia da infância
}

\author{
Gabriela Guarnieri de Campos Tebet \\ Anete Abramowicz \\ Universidade Federal de São Carlos
}

\section{Resumo}

Este artigo tem como objetivo constituir teoricamente a categoria bebê, no interior da sociologia da infância, tal como o fez Chris Jenks, em 1982, em relação à criança, a partir de seu texto "Constituindo a criança". A partir de uma pesquisa fundamentada nos aportes da genealogia (tal como proposta por Foucault), problematizamos a utilização de conceitos e metodologias para o estudo dos bebês, propostos pela sociologia da infância tais como os conceitos de infância, geração, e culturas de pares e a partir da análise da produção teórica e bibliográfica de autores da sociologia da infância de língua inglesa, ressaltamos a necessidade de constituirmos teoricamente o bebê como um conceito e uma categoria analítica independente.

Palavras-chave: Bebê. Diferença. Singularidade. Sociologia da Infância. Metodologia de Pesquisa. 


\section{The baby interrogates sociology of childhood}

The aim of this article is to constitute theoretically the category "baby" within the Sociology of Childhood, as Chris Jenks did in 1982, for the child, initially in his text "Constituting the child." From a study based on the contributions of genealogy las proposed by Foucault), we discuss the use of concepts and methodologies, proposed by the Sociology of Childhood for the study of babies, such as the concepts of childhood, generation and peer cultures. Based on an analysis of the theoretical and bibliographical production of English-language authors in Sociology of Childhood, we emphasize the need to constitute the baby theoretically as a concept and independent analytical category.

Keywords: Baby. Difference. Singularity. Sociology of Childhood. Research Methodology.

\section{Los bebés interrogan la sociología de la infancia}

Este artículo tiene por objetivo constituir teóricamente la categoría bebé en el interior de la Sociología de la Infancia, tal como lo hizo Chris Jenks, en 1982, con relación al niño, en su texto "Constituyendo el niño". Desde una investigación que se fundamenta en las contribuciones de la genealogía (así como se propuso hacer Foucault), problematizamos la utilización de los conceptos y metodologías para el estudio de los bebés propuestos por la Sociología de la Infancia, son ellos: los conceptos de infancia, generación y la cultura de iguales. Y desde el análisis de la producción teórica y bibliográfica de los autores de la Sociología de la Infancia de la lengua inglesa, señalamos la necesidad de que el bebé sea constituido teóricamente como un concepto y como una categoría analítica independiente.

Palabras clave: Bebé. Diferencia. Singularidad. Sociología de la Infancia. Metodología de la Investigación. 


\section{Introdução}

\section{Bebês}

Este texto tem como objetivo constituir teoricamente a categoria bebê, no interior da sociologia da infância, tal como o fez Chris Jenks, em 1982, em relação à criança, a partir de seu texto "Constituindo a criança". De acordo com o autor, naquele momento fazia-se necessário empreender um esforço de constituir a criança teoricamente, frente às abordagens que abandonavam as crianças “quer à ignorância e a um estatuto secundário, quer a uma diferença radical e a um mundo bipartido" (Jenks, 2002, p. 214). Desde então, e a partir de outras tantas publicações de autores diversos (vide, por exemplo, James e Prout, 1990; Qvortrup, 1993; Corsaro, 1997; Alanen e Mayall, 2001), temos observado avanços constantes nos estudos da infância e das crianças, no sentido de definir teoricamente os conceitos "criança" e "infância" e avançar no sentido de olhar para as crianças numa perspectiva social. Este movimento de tomar a criança e a infância como perspectiva analítica colocando-as no centro do campo teórico vem sendo denominado sociologia da infância e/ou estudos da criança. No entanto, de toda a maneira, no interior deste campo, secundarizaram-se os bebês.

Ao longo das últimas décadas, novos olhares se voltaram para as crianças, vistas não mais como seres meramente biológicos ou como um modelo ideal e abstrato de criança, mas como sujeitos sociais marcados pela pluralidade de contextos sociais, étnico-raciais culturais e históricos que as constituem. Observamos um avanço das teorias sociológicas em relação às crianças e ao conceito de infância em especial naquilo que significou o abandono de uma concepção universal e de desenvolvimento de criança; todavia, os bebês continuam ocupando apenas uma condição marginal em tais teorias.

A pesquisa realizada (Tebet, 2013) e cujos resultados aqui apresentamos de forma parcial, configura-se como uma pesquisa analítica a partir dos aportes da genealogia tal como proposta por Foucault e que visa constituir teoricamente 0 bebê, confrontando-o com os aportes analíticos do campo da sociologia da infância. Deste modo, no presente artigo, partimos de um estudo das ideias dos principais teóricos da Sociologia da Infância de língua inglesa, identificamos as teorias, os conceitos e as metodologias que embasam seus pensamentos, e buscamos compreender de que modo eles poderiam nos ajudar a constituir o bebê como uma categoria analítica e um objeto de interesse da Sociologia da Infância e quais metodologias seriam adequadas para as pesquisas com bebês.

Para isso, dialogamos com a "Sociologia do Discurso da Criança e da Infância" de James, Jenks e Prout, fundamentada no pensamento pós-estrutural de 
Foucault, Deleuze, Guattari e Bataille; com a “Sociologia da Infância Estrutural” que vem sendo defendida por Jens Qvortrup, a partir de uma construção analítica que toma alguns dos pressupostos do referencial marxista, como ponto de partida, em especial, ao tomar a infância como categoria estruturante da sociedade, isto quer dizer, fazer da infância um conceito estrutural e permanente lque se opõe à ideia psicológica de fase passageiral, mas que migra de uma perspectiva de classe social para uma perspectiva geracional; com a "Sociologia das Crianças", de William Corsaro respaldada na Sociologia de Goffman, Giddens e na antropologia de Geertz e com a “sociologia da Infância Relacional”, de Leena Alanen e de Berry Mayall, assente na teoria de Pierre Bourdieu.

Cada uma dessas abordagens nos traz implicações diversas para o estudo dos bebês e para o campo teórico dos estudos da criança e da infância. Cada uma delas se interessa por questões distintas e se apoia em metodologias próprias e não devem ser vistas como concorrentes, devendo ser compreendidas como "lentes complementares a serem utilizadas para pesquisar crianças e suas condições sociais". (Alanen, 2004, p. 6 - livre tradução)

Assim, o estudo dessas abordagens nos mostra que não cabe tratar a sociologia da infância como "um referencial teórico-analítico", tampouco como "um referencial metodológico" para o estudo das crianças ou da infância. A sociologia da infância se apresenta antes como um campo de conhecimento composto por diversos referenciais teóricos, metodológicos e analíticos, algumas vezes complementares, outras vezes antagônicos, e que precisam ser evidenciados, pois não são homogêneos, não levam às mesmas compreensões e nem produzem os mesmo efeitos.

A escolha dos teóricos "de língua inglesa" se deu em virtude da importante contribuição que eles têm dado ao campo, tal como apontado por Montandon (2001) e devido ao fato de que entre os autores de língua inglesa foi possível encontrar autores protagonistas das diferentes abordagens da sociologia da infância. Por esta razão, e tendo em vista ainda que o objetivo deste texto é discutir os fundamentos teórico-metodológicos das distintas abordagens da "sociologia da infância" e tentar considerar alguns elementos teóricos para a inclusão dos bebês nesse campo de estudos, optamos por delimitar nosso campo de investigação aos trabalhos de autores de língua inglesa, a fim de garantir um recorte que incluísse uma maior variedade de fundamentos teóricos e metodológicos, bem como que incluísse os autores que sustentam cada uma das abordagens com as quais vamos dialogar. Isto feito, elegemos os principais textos publicados por esses autores em livros e revistas científicas e realizamos uma análise dos principais temas e conceitos presentes na obra de cada autor e das metodologias utilizadas, tendo em vista visibilizar os aspectos que poderiam contribuir para o estudo dos bebês. 
No interior desse movimento, iluminamos a presença/ausência dos bebês no interior do campo da infância e indicamos algumas linhas para que eles possam ser pensados mais singularmente. Entendemos que olhar para os bebês, a partir da sociologia da infância (ou da antropologia, da geografia, da filosofia, etc.) implica reconhecer a especificidade dos bebês na tessitura social, bem como reconhecer as limitações do campo para o seu estudo. Implica ultrapassar a fase de "extensão conceitual" e inaugurar uma fase de "reconstrução teórica", tal como ocorreu com os estudos da infância e com os estudos feministas (Alanen, 2010). É este movimento que buscamos iniciar aqui, a partir do diálogo com as distintas abordagens da sociologia da infância de língua inglesa.

\section{Um diálogo com as sociologias da infância estruturais}

No interior das sociologias da infância estruturais, Alanen (2001b, 2010, 2012) indica a existência de duas perspectivas distintas: a sociologia da infância estruturacategorial e sociologia da infância estrutural-relacional. A primeira é marcada pelas ideias de Qvortrup e pela centralidade dos conceitos “infância”, “geração” e "estrutura" em sua obra. A segunda tem como principais autoras Berry Mayall e a própria Leena Alanen e adota como conceitos centrais o "campo" e a "estruturação geracional”, numa perspectiva relacional. 0 propósito deste enfoque consiste em incluir as crianças e a infância no pensamento sociológico: as crianças como agentes nas relações sociais e a infância como grupo social fundamentalmente implicado nos processos sociais relacionais. Esta concepção enfatiza a desigual distribuição de poder e status entre as gerações, propondo que se aproveite as teorias sociais e a luta feminista na luta política por representação.

A partir de estudos macroestruturais e comparativos, o sociólogo dinamarquês Jens Qvortrup em diversas de suas publicações (Qvortrup, 1993, 1994, 1999, 2002, 2005a, 2005b, 2005c) busca definir a infância em termos conceituais, isto é, em termos daquilo que é comum a todas as crianças e destaca para isso, a importância de que pesquisas estatísticas adotem as crianças como uma categoria independente de análise de dados, oferecendo assim elementos para pesquisas sobre a infância. Ou seja, a infância nesta perspectiva é um elemento permanente e parte da estrutura social das sociedades modernas; e também, como uma "estrutura" em si mesma, comparável e análoga à classe social e ao gênero, por exemplo, uma categoria analítica.

No que diz respeito ao estudo dos bebês, ressaltamos as limitações dos conceitos trazidos por alguns autores de perspectiva estrutural e apontamos que para os bebês, a infância existe apenas como potencialidade, mas nunca como coletividade 
ou realidade concreta (Mannheim, 1982), pois a ideia de "geração enquanto realidade" envolve a existência de um nexo concreto entre os participantes de uma dada geração, que não ocorre no caso dos bebês, e a noção de "estrutura" pouco contribui para o estudo da condição singular vivida pelos bebês.

Assim, ainda que pesquisas macroestruturais e comparativas possam ser realizadas tendo os bebês como categoria analítica, pesquisas dessa natureza somente nos proverão de informações sobre a geração dos bebês como potencialidade.

Numa perspectiva distinta, Alanen (2009b) parte de um diálogo com Pierre Bourdieu para discutir a infância a partir de uma abordagem estruturalrelacional. Para a autora, as estruturas geracionais não são estruturas fixas, predefinidas em toda sociedade, já que são construídas por meio das relações sociais. Alanen destaca a existência de redes de relações por meio das quais as gerações são construídas cotidianamente, e adota como conceito-chave em seu trabalho as noções de "estruturação geracional" (Alanen, 2001b, 2001c, 2009a, 2012), “ordenamento geracional" (Alanen, 2001c, 2009a), “campo" e "geração social” (Bourdieu, 1983; Bourdieu; Wacquant,1992). Em termos metodológicos, Alanen propõe o estudo das disputas intergeracionais existentes no interior de cada campo e o papel desempenhado por seus agentes e atores, isto é, propõe a análise dos campos, tal como definida por Bourdieu.

No interior da perspectiva estrutural, a abordagem proposta por Alanen tem a vantagem de levar em consideração as redes de relações que envolvem os bebês. A teoria dos campos de Bourdieu e a metodologia de pesquisa a ela inerente permitem estudarmos a posição ocupada pelos bebês em distintos campos (tal como a família), bem como as práticas e relações por meio das quais os bebês deixam de ser meros participantes amadores e progressivamente se constituem como agentes no interior dos campos de que participam, passando assim da condição de bebê para a condição de criança. Mas mesmo assim a ideia de campo é insuficiente para entender o percurso dos bebês, pois estes infletem singularmente os lugares, o espaço e também o tempo, como destacaremos ao apresentar as contribuições da sociologia do discurso das crianças e da infância.

\section{Um diálogo com a sociologia das crianças}

A fim de compreender melhor as contribuições da sociologia das crianças, trouxemos para o debate as ideias de William Corsaro, um dos principais teóricos desta abordagem. 0 autor se pauta nas ideias de Goffman, Giddens e Geertz e adota como conceitos centrais as noções de "culturas de pares" ou "culturas 
infantis". Seus estudos utilizam como metodologia a etnografia, a fim de captar os elementos das culturas infantis. A partir da interpretação dessas culturas, Corsaro desenvolve o conceito de "reprodução interpretativa" para se remeter às características produtivas e reprodutivas que marcam as culturas das crianças. Isto quer dizer que as crianças não se limitam a imitar, a se adaptar ou a aprender a cultura que as rodeiam, mas participam ativamente e reinterpretam os elementos da rotina cultural. 0 termo interpretativo trazido por Corsaro, portanto:

[...] se refere aos aspectos inovadores e criativos da participação das crianças na sociedade: as crianças criam e participam em sua própria e única cultura de pares tomando e apropriando-se de informações do mundo adulto para levá-la a sua própria cultura. 0 termo reprodução refere-se à ideia de que as crianças não internalizam simplesmente a sociedade e a cultura, sim que contribuem ativamente para sua produção. (Gaitan, 2006, p.27)

Todavia, a ideia de culturas de pares não se aplica aos bebês, que de acordo com Corsaro, possuem uma ação limitada nas rotinas culturais e não constituem "grupos de pares". 0 uso do conceito de culturas pode ser ainda problematizado tendo-se em vista que "não existe uma única definição correta do termo cultura". Kroeber e Kluchohn (1952, apud Brah, 2011), por exemplo, reuniram segundo o livro Cartografias da Diáspora - 164 definições distintas de cultura.

Assim, em face à insuficiência dos conceitos "cultura", e "grupos de pares" para os estudos dos bebês, propomos um diálogo com o conceito de "processos de singularização" e com a cartografia proposta por Guattari e Rolnik (1986). No que se refere à cartografia, Rolnik (1989, p. 15) afirma que:

Para os geógrafos, a cartografia - diferentemente do mapa, representação de um todo estático, - é um desenho que acompanha e se faz ao mesmo tempo que os movimentos de transformação da paisagem. Paisagens psicossociais também são cartografáveis. A cartografia, nesse caso, acompanha e se faz ao mesmo tempo que o desmanche de certos mundos - e a formação de outros: mundos que se criam para expressar afetos contemporâneos, em relação aos quais os universos vigentes tornam-se obsoletos.

Nesta perspectiva, propomos como possibilidade cartográfica com os bebês, as cartografias que são traçadas por Fernand Deligny em seu trabalho com crianças autistas. Deligny (1913-1996) é um educador francês especialista em trabalho com crianças autistas, e um trabalho que merece ser destacado foi a direção do filme "Le Moindre Geste", entre os anos de 1962 e 1964. Ele propõe que se acompanhem as linhas, os movimentos, os gestos dos autistas, não para 
compreender ou interpretar seus gestos, mas para - ao seguir estas linhas, os desvios, o nada - ver e cartografar a maneira pela qual eles revelam uma maneira singular de ser, de se relacionar com o espaço, com o tempo, a memória, etc. Esta possibilidade não será totalmente explorada neste momento, mas deixamos registrada a enorme possibilidade metodológica que poderia ser aprofundada por aqueles que trabalham com os bebês ao seguir o trabalho proposto por Deligny.

No que se refere às propostas de Corsaro, destacamos a potencialidade do seu modelo da teia global para o estudo das redes e agenciamentos criados pelos bebês nos diversos espaços e campos em que estão inseridos e voltamos a insistir na cartografia como uma metodologia que permite considerar o bebê em toda a sua singularidade, sendo a esquizoanálise (Guattari, 1985) e a elaboração de mapas de trajetos e de afetos (Deleuze, 1997) algumas alternativas possíveis para as pesquisas com bebês. É na esteira do pensamento rizomático em Deligny, Deleuze e Guattari que propomos a construção de uma metodologia de pesquisa com bebês.

Por fim, ponderamos que esses debates, aqui iniciados, são apenas parte de um movimento que já vem sendo esboçado e que visa trazer para as pesquisas sobre bebês, as contribuições dos estudos da infância, fazendo também dos bebês um objeto de interesse da sociologia da infância. Todavia, esse casamento não pode ocorrer a partir da simples extensão dos conceitos de criança e de infância da sociologia da infância para o estudo dos bebês. Porque os bebês não são crianças! Assim, nem todos os conceitos, e nem todas as metodologias que se aplicam aos estudos das crianças são adequados ao estudo dos bebês.

\section{Um diálogo com a sociologia do discurso das crianças e da infância}

0 debate realizado por esta abordagem se assenta nos conceitos de "regimes de verdade", "discurso" e "controle", "governamento das crianças" e outros de Michel Foucault, e no conceito de "rizoma", de Gilles Deleuze e Félix Guattari e tem como principais representantes Chris Jenks, Allison James e Alan Prout (Vide Jenks, 2002, James e Prout, 2007; James, Jenks e Prout, 1998). De acordo com Alanen (2012), esta abordagem se fundamenta numa perspectiva pós-positivista que entende a criança e a infância como uma formação semiótica e discursiva, uma construção social e cultural que comunica uma determinada "verdade".

Todavia, para além desta compreensão da infância como construção discursiva, e tendo em vista o debate proposto por Prout $(2005,2010)$ e Jenks $(2005 b)$, trazemos à tona os conceitos de "transgressão" (Foucault, 2006; Bataille, 2001, citado por Jenks, 2005b), “imanência” (Deleuze, 1995; Prout, 2005) e elementos da teoria 
do ator-rede (Latour, 1993 citado por Prout, 2005, 2010) que nos permitem outro olhar para a criança e para o bebê.

A ideia de transgressão utilizada por Jenks vincula-se à ideia de limite, não havendo um sem que haja o outro. De acordo com Suleiman, "a experiência da transgressão é indissociável da consciência das limitações e proibições que ela viola; de fato, é precisamente por meio da sua transgressão que a força da proibição se torna plenamente realizada". (Suleiman, 1990, p. 118, citado por Jenks, 2005b)

Deste modo Jenks afirma, concordando com Foucault (2006), que a transgressão não é algo negativo, mas sim o desígnio da diferença que rompe com a noção de normalidade. É a negação do modelo que possibilita a experimentação da liberdade e faz emergir as singularidades.

Tendo em vista que o modelo social adotado na maior parte das sociedades é um modelo adultocêntrico, que assume o padrão adulto de linguagem, conduta e relacionamentos como o padrão de normalidade, a criança não pode ser compreendida senão como representante da patologia, da diferença e da transgressão - um anormal -, uma vez que não se enquadra no modelo adulto: elas "ignoram as normas, as regras e as convenções da sociedade adulta" (Jenks, 2005, p. 122) e "destacam, uma vez mais, a infatigável, inerente e infinitamente variável capacidade humana de transgredir." (Jenks, 2005, p. 127)

De acordo com o autor, as transgressões das crianças expõem a fragilidade do poder adulto, mas elas não visam criticar a ordem, ao contrário, são inerentes ao sistema normativo, de modo que o estudo das transgressões pode nos oferecer dados para a análise dos nossos meios de controle dominantes e podem oferecer subsídios para refletirmos sobre a base moral dos nossos limites sociais.

Inicialmente, seria possível afirmarmos que o conceito de transgressão proposto para o estudo das crianças não se aplica ao estudo dos bebês, considerando que esses não possuem consciência das regras que transgridem e que, para Foucault (2006), esta é uma das características da transgressão. Porém, ainda assim, o conceito de transgressão e, sobretudo, a metodologia de pesquisa a ele inerente podem ser significativamente úteis para o estudo dos bebês, uma vez que o conceito de transgressão existe fora da linguagem e permite contornar o problema da não compreensão da linguagem dos bebês por parte dos pesquisadores, apontado, entre outros, por Gottlieb (2009). Trata-se de um conceito útil, sobretudo tendo em vista que os bebês se singularizam a partir de agenciamentos que fazem na relação com as pressões e as forças sociais, o que poderia ser compreendido de certo modo como um tipo de transgressão.

De acordo com Foucault, "a linguagem está quase inteiramente por nascer onde a transgressão encontra seu espaço e seu ser iluminado" (Foucault, 2006, p. 32). 0 pensamento transgressivo, deste modo, não possui um modelo, um fundamento, 
nem tampouco um vocabulário ou linguagem própria e o desafio que se coloca é "tentar falar dessa experiência e fazê-la falar no próprio vazio da ausência de sua linguagem, lá onde precisamente as palavras the faltam”. (Foucault, 2006, p. 3637)

Este é também o desafio que se coloca para as pesquisas com bebês e que precisa ser vencido e a metodologia que se coloca para o estudo dessa diferença, dessa singularidade que a transgressão constitui. É o estudo da singularidade em oposição à individualidade do ser que precisa ser configurado assim como a produção e invenção de conceitos para dar conta desta singularidade que habita o bebê. É o estudo das linhas de imanência que marcam, especialmente, a vida dos bebês e que independe da linguagem dos seres singulares em questão.

\section{Constituindo o conceito "bebê" no interior da sociologia da infância}

A partir das ideias expostas até o momento, constituímos o conceito "bebê" como singularidade e imanência, em diálogo com as teorias que sustentam 0 pensamento de Prout $(2005,2010)$ e Jenks (2005b).

De acordo com Prout (2005, p.113):

As crianças se esforçam para se tornar aquilo que elas desejam ser, criando o que Deleuze define como uma 'linha (ou plano) de imanência'. A criação dessa linha envolve uma dupla atividade. Crianças traçam uma trajetória que negocia as mais rígidas estruturas e expectativas estabelecidas ao seu redor, o que Deleuze denomina como 'linhas (ou planos) de organização'.

Essas linhas de organização incluem as instituições, tais como a família e a escola, que visam moldar as crianças, fixando-as no interior de um padrão de normalidade lem geral marcado pelas dicotomias binárias natureza/cultura, homem/mulher, adulto/criança, etc.). Todavia, as crianças frequentemente escapam dessas imposições. Por meio das linhas de imanência, elas “dissolvem essas segmentalizações e divisões binárias, ignorando e hibridizando-as e criando novas entidades". (Prout, 2005, p. 113)

Compreender os bebês a partir dos conceitos de vida singular e imanência é, portanto, compreendê-los como seres pré-individuais, tendo em vista que, de acordo com Deleuze (2010, p. 118), é a singularidade que marca a condição préindividual do ser. 0 autor afirma: 
Singular sem ser individual, eis o estado do ser pré-individual. Ele é diferença, disparidade, disparação [...] Mundo imbricado de singularidades discretas, tanto mais imbricado quanto mais estas não estejam ainda se comunicando ou não estejam tomadas numa individualidade: é este o primeiro momento do ser.

Há de se destacar aqui que a noção de singular nada tem a ver com o debate entre infância plural ou singular travado entre os sociólogos da infância de língua inglesa. No interior desse debate que propomos a compreensão da singularidade do bebê implica, portanto, pensar o conjunto dos bebês como plural e nunca como singular.

Nesta perspectiva, este primeiro momento do ser ao qual o Deleuze se remete pode ser denominado como "natureza", tal como indica Simondon, se essa for entendida no sentido pré-socrático, como a condição do possível e do indeterminado e não como o contrário do homem. Natureza compreendida como a primeira etapa da vida humana, como a condição do ser pré-individual.

0 conceito de bebê que constituímos, portanto, é o conceito do bebê como ser singular, pré-individual. Os bebês são o devir, são exemplos de diferença e carregam consigo a potencialidade de fazer emergir novas formas de ser, de relacionar-se e de viver. Nesse sentido, são natureza (Simondon) porque ainda não assimilaram as regras e as restrições sociais do "plano de organização", porque ainda não se configuraram como indivíduos. Estão imersos num plano de imanência e de possibilidades. De acordo com Deleuze (1995, s/p):

As singularidades ou os acontecimentos constitutivos de uma vida coexistem com os acidentes da vida correspondente, mas não se agrupam nem se dividem da mesma maneira. Eles se comunicam entre si de uma maneira completamente diferente da dos indivíduos. Parece mesmo que uma vida singular pode passar sem qualquer individualidade ou sem qualquer outro concomitante que a individualize. Por exemplo, os recém-nascidos são todos parecidos e não têm nenhuma individualidade; mas eles têm singularidades, um sorriso, um gesto, uma careta, acontecimentos, que não são características subjetivas. Os recém-nascidos, em meio a todos os sofrimentos e fraquezas, são atravessados por uma vida imanente que é pura potência, e até mesmo beatitude.

Ao assumir essa concepção do bebê como um ser pré-individual e singular, há de se refletir sobre trajetos, por meio dos quais os bebês transitam, entre os planos de imanência e de organização, e sobre as relações, a partir das quais paulatinamente os bebês são individuados. Há de se refletir e cartografar os processos de singularização, bem como sobre a carga de pré-individualidade que 
permanece na criança (e mesmo no adultol após o processo de individuação, e que é compreendida como uma fonte de metaestabilidade capaz de produzir novas individuações.

Nesta perspectiva e tendo em vista as propostas teóricas e metodológicas de estudo da infância trazidas por Prout $(2005,2010)$, aponta-se que a teoria do atorrede de Latour (apresentada por Prout, 2005, 2010) e a cartografia (dos trajetos e dos afetos) de Deleuze e Guattari (apontada por Deleuze, 1997 e mencionada por Prout, 2005) e acrescentamos as linhas errantes e de circulação que traça Deligny e que podem trazer interessantes possibilidades para as pesquisas com bebês na perspectiva aqui indicada.

Na teoria do ator-rede à qual Prout (2010) se remete, tanto a sociedade, como as organizações, os agentes e as máquinas são compreendidos como resultados de uma rede heterogênea constituída da relação de elementos humanos (atores) e não humanos (actantes). Dessas interações, podem emergir inúmeras versões de crianças ou de adultos e a questão central, nessa perspectiva é, portanto, "verificar como diferentes versões de criança ou adulto emergem da interação complexa, das redes e da orquestração de diferentes materiais naturais, discursivos, coletivos e híbridos".(Prout, 2010, p. 747)

A ideia de rede, defendida por Latour, aproxima-se muito da ideia de rizoma de Deleuze e Guattari e demanda a compreensão de fluxos e o estudo dos deslocamentos de objetivos, interesses, dispositivos e seres humanos. Implica observar o "desvio de rota, invenção de um elo que antes não existia e que de alguma maneira modifica os elementos imbricados". (Freire, 2006, p. 51)

Deste modo, uma perspectiva metodológica que potencializa o debate oferecido pela teoria do ator-rede, é aquela que tenha como foco a ação, em lugar do fato e que seja "capaz de cartografar tais redes em termos de sua geografia - principais actantes, porta-vozes e respectivas conexões - e de sua dinâmica - fluxos das diferentes traduções".(Nobre; Pedro, 2010, p. 52)

De acordo com Nobre e Pedro, nesse processo a preocupação do pesquisador deve ser o registro e não a interpretação. Eles afirmam (Nobre; Pedro, 2010, p. 54):

Assim como um detetive que rastreia as ruelas enigmáticas do seu caso investigativo, nós devemos seguir as pistas que aparecem a cada momento, os mediadores que nos convocam a desviar, construir caminhos, costurar circuitos. Uma frase ecoa nesse momento: “[...] registrar, não filtrar; descrever, não disciplinar." (Latour, 2008, p. 86). Desse modo, devemos buscar seguir tais indícios, aplainando um terreno ruidoso, por meio de uma cartografia, focalizando nos mediadores; nenhuma explicação que reporte a uma dimensão de profundidade, apenas o terreno sinuoso dos deslocamentos e seu mapeamento. 
Tal como nos escritos de Foucault, há uma rejeição a qualquer esforço de interpretação. Na teoria do ator-rede há uma necessidade de descrever sem explicar (Freire, 2006), razão pela qual a cartografia torna-se um instrumento interessante, sobretudo se considerarmos que, de acordo com Deleuze, as crianças estão sempre envolvidas em "explorar os meios, por trajetos dinâmicos, e traçar o mapa correspondente" (Deleuze, 1997, p. 73), atividade inerente também aos bebês, uma vez que de acordo com o autor Deleuze (1997, p. 74):

Não existe momento algum em que a criança não esteja mergulhada num meio atual que ela percorre, em que os pais como pessoas só desempenham a função de abridores ou fechadores de portas, guardas de limiares, conectores ou desconectores de zonas. Os pais estão sempre em posição num mundo que não deriva deles. Mesmo no caso do bebê, os pais se definem em relação a um continente-cama como agentes nos percursos da criança.

Assim, estudar os bebês não é estudar o indivíduo, assim como não é estudar nenhuma verdade objetiva dada a priori. É estudar o devir. Como afirma Deleuze (1997, p. 77):

Vemos claramente porque o real e o imaginário tinham de ser superados, ou mesmo intercambiar-se: um devir não é imaginário, assim como uma viagem não é real. É o devir que faz, do mínimo trajeto ou mesmo de uma imobilidade no mesmo lugar, uma viagem; e é o trajeto que faz do imaginário, um devir. Os dois mapas, dos trajetos e dos afetos, remetem um ao outro.

Estudar os bebês é, portanto, estudar as redes que constituem as crianças e os movimentos dos bebês entre esses planos de imanência e de organização, cartografando os trajetos e os afetos, que constituem os movimentos das crianças e registrando, assim, as singularidades inerentes à condição pré-individual do bebê.

Este é o horizonte que se coloca para as pesquisas com bebês a partir da abordagem proposta pelos teóricos com os quais dialogamos neste item e é também o horizonte que aqui defendemos.

\section{Considerações finais}

A partir das ideias apresentadas pelos autores, construímos a noção de que os bebês podem ser compreendidos como seres pré-individuais, imersos em uma 
condição de metaestabilidade onde tudo escapa. Onde tudo é potência e nada está dado. Os bebês são, deste modo, constituídos como devires, seres singulares, que habitam um sistema "problemático", do ponto de vista dos adultos - que é esse momento anterior à infância e que pode ainda ser definido como caos. (Abramowicz, 2011, p. 18)

A condição do bebê não está, portanto, vinculada a uma idade específica. Não há uma data para se deixar de ser um bebê, assim como não há um ritual específico de passagem da condição de bebê para a condição de criança. 0 que existem são processos de individuação que ocorrem por meio das inúmeras redes que os bebês constroem com os seres humanos e não humanos (atores e actantes) ao seu redor. Processos que fazem da diferença, identidade.

Quando a individuação ocorre, o caos se torna administrado, a diferença se evade e há uma solução para aquele sistema problemático. Então o bebê sai daquela condição caótica de instabilidade para se constituir como criança. Mas a condição pré-individual permanece associada a ele lassim como está associada a todo indivíduol como fonte de estados metaestáveis futuros e é somente em razão dessa condição pré-individual, que novas possibilidades se abrem para os indivíduos e novas individuações podem ocorrer ao longo da vida.

A partir destes conceitos, apontamos para a necessidade de metodologias de pesquisa que sejam capazes de lidar com essa condição inerente ao bebê. Metodologias que busquem compreender os bebês, seus movimentos e as redes tecidas por eles, com eles e para eles. Apontamos metodologias capazes de olhar para o bebê em sua potência e singularidade e nos remetemos ao método transgressivo de Bataille (citado por Jenks, 2005), às metodologias propostas pela teoria do ator-rede (discutida por Prout, 2010) e à cartografia proposta por Deleuze/ Guattari/ Deligny como algumas alternativas promissoras.

A partir dessas reflexões defendemos a ideia de que a condição vivida pelo bebê é distinta da condição da criança, uma vez que a criança é um ser que, de algum modo, já foi individuado, apesar de "habitar" também na condição pré-individual, já constituiu para si uma identidade geracional, de gênero, de raça, de pertencimento familiar e de pertencimento a um grupo de amigos, enquanto o bebê é um ser ainda totalmente preenchido de uma condição pré-individual, o bebê não construiu ainda a sua identidade, ele é o devir, é a singularidade da diferença e a potencialidade de fazer emergir novas formas de ser e de relacionar-se. 


\section{Referências}

ABRAMOWICZ, Anete. A pesquisa com crianças em infâncias e a sociologia da infância. In: FARIA, Ana Lúcia Goulart de; FINCO, Daniela. Sociologia da infância no Brasil. Campinas: Autores Associados, 2011.

ALANEN, Leena. Estudos Feministas/Estudos da Infância: paralelos, ligações e perspectivas. In: CASTRO, Lucia Rabello de (Org.). Crianças e jovens na construção da cultura. Rio de Janeiro: NAU, 2001a. p. 69-92.

. Explorations in generation analysis. In: ALANEN, Leena; MAYALL, Barry. Conceptualizing child-adult relations. London, New York: Routledge/Falmer, 2001 b. p. 11-23.

Childhood as a generational condition: children's daily lives in a central Finland town. In: Conceptualizing child-adult relations. London, New York: Routledge/Falmer, 2001 c. p. 129-144.

. Theorizing children's welfare. Trabalho apresentado no Wellci network workshop 1: New perspectives on childhood. Leeds, Reino Unido, 2004. Disponível em: <http://ciimu.org/webs/wellchi/reports/workshop_1/w1_alanen.pdf>. Acesso em: 30 mar. 2013.

. Generational Order. In: QVORTRUP, Jens; CORSARO, William; HONIG, Michael-Sebastian. The palgrave handbook of vhildhood studies. London: Palgrave Macmillan, 2009a. p. 159-174.

Rethinking childhood with Bourdieu. In: MARKSTRÖM, Ann-Marie et al. (Eds.). Barn, barndomochföräldraskap. Stockholm: CarlssonsBokförlag, 2009b. p. 307-324.

Teoria do bem-estar das crianças. Cadernos de Pesquisa, São Paulo, v. 40, n. 141, Tema em destaque: estudos sociais sobre a infância. p. 689-691, set./ dez. 2010.

. L'infanzia come concetto generacionale. In: HENGST, Heinz; ZEIHER, Helga (Orgs.). Per uma Sociologia dell'infanzia. Milão: Franco Angeli, 2012.

; MAYALL, Barry. Conceptualizing child-adult relations. London, New York: Routledge/Falmer, 2001.

BOURDIEU, Pierre. O Campo Científico. In: ORTIZ, Renato (Org.). Pierre Bourdieu - sociologia. São Paulo: Editora Ática, 1983. Coleção Grandes Cientistas Sociais.

; WACQUANT, Loic. An invitation to reflexive sociology. Chicago: The University of Chicago Press, 1992.

BRAH, Avtar. Cartografia de la diaspora: identidades em cuestión. Madrid: La edición Traficantes de Sueños, 2011.

COHN, Clarice. Antropologia da infância. 2. ed. Rio de Janeiro: Zahar, 2009.

CORSARO, William. The Sociology of Childhood. Thousand Oaks. California: Pine 
Forge Press, 1997.

. Sociologia da infância. 2. ed. Tradução de Lia Gabriele R. Reis. Porto Alegre: Artmed, 2011.

DELEUZE, Gilles. A imanência: uma vida... Publicado originalmente em Philosophie, n. 47, 1995. p. 3-7. Tradução de Tomaz Tadeu da Silva. Disponível em: <http:// pt.scribd.com/doc/7182897/Deleuze-Gilles-A-Imanencia-Uma-Vida>. Acesso em: 30 mar. 2013.

. 0 que as crianças dizem. In: DELEUZE, Gilles. Crítica e clínica. Tradução de Peter Pelbart. São Paulo: Editora 34, 1997. p. 73-79.

. Gilbert Simondon, o indivíduo e sua gênese físico-biológica [1966]. In: DELEUZE, Gilles. A ilha deserta. São Paulo: Iluminuras, 2010.

;GUATTARI, Felix. Mil platôs. Capitalismo e Esquizofrenia.v. 1. Coordenação da tradução: Ana Lúcia de Oliveira. São Paulo: Editora 34, 2000.

DELIGNY, Fernand. L'arachnéen et autres textes. Paris: Ed. Arachnéen, 2008.

. Cartes et Lignes D'Erre. Traces du réseau de Fernand Deligny 1969-1979. Paris: L'Arachnéen, 2013.

FOUCAULT, Michel. Isto não é um cachimbo. Tradução de Jorge Coli. 3. ed. Rio de Janeiro: Paz e Terra, 1988.

. As palavras e as coisas. Tradução de Salma T. Muchail. São Paulo: Martins Fontes, 1995.

A verdade e as formas jurídicas. 2. ed. Rio de Janeiro: Nau Editora, 1999.

Vigiar e punir. Petrópolis: Vozes, 2004.

1963 - Prefácio à transgressão. In: FOUCAULT, Michel. Estética: Literatura

e Pintura, Música e Cinema. Rio de Janeiro: Forense Universitária, 2006. (Ditos e Escritos III).

. Microfísica do poder. São Paulo: Graal, 2011.

FREIRE, L. Seguindo Bruno Latour: notas para uma antropologia simétrica. Comum, Rio de Janeiro, v. 11, n. 26, p. 46-65, jan./jun. 2006. Disponível em: <www. ifcs.ufrj.br/ lemetro/pesquisadores/Leticia\%20de\%20Luna\%20Freire/latour. pdf>. Acesso em: 30 mar. 2013.

GAITAN, Lourdes. Sociologia de la infancia - análisis e intervención social. Madrid: Editorial Síntesis S/A, 2006.

GOTTLIEB, A. Para onde foram os bebês? Em busca de uma antropologia de bebês (e de seus educadores). Psicologia USP, São Paulo, v. 20, n. 3, jul./set., 2009.

GUATTARI, Felix. Pistas para uma esquizoanálise - os oito princípios. In: GUATTARI, Felix. Revolução Molecular: pulsações políticas do desejo. São Paulo: Brasiliense, 1985.

1986.

; ROLNIK, Suely. Micropolítica: cartografias do desejo. Petrópolis: Vozes, 
JAMES, Allison; JENKS, Chris; PROUT, Alan. Theorizing childhood. Cambridge: PolityPress, 1998.

. O corpo e a infância. In: KOHAN, Walter O.; KENNEDY, Dorothy. Filosofia e infância: possibilidades de um encontro. 2. ed. Petrópolis: Editora Vozes, 2000. p. 207-238.

JAMES, Allison; PROUT, Alan. Constructing and Reconstructing Childhood: contemporary Issues in the Sociological Study of Childhood. London, New York: RoutledgeFalmer, 2007 (1. ed., 1997).

JENKS, Chris. (Org.). The Sociology of childhood. Essential readings. Brookfield, VT: Gregg Revivals, 1982.

. Constituting the child. In: JENKS, Chris (Ed.). The sociology of childhood: Essential readings. London: Batsford, 1982.

- Constituindo a criança. Revista Educação, Sociedade e Culturas, Porto, n. 17, 2002. Disponível em: <www.fpce.up.pt/ciie/revistaesc/pagina17.htm>. Acesso em: 30 mar. 2013.

. Childhood and Transgression. In: QVORTRUP, J. Studies in modern childhood. Palgrave: MacMillan, 2005. p. 115-127.

MAGRITTE, R. Ceci n'est pas une pipe. 1929.

MANNHEIM, Karl. The sociological problem of generation. In: MANNHEIM, Karl. Essays on the sociology of knowledge. Londres: Routledgeand Kegan Paul Ltd., 1952. p. 286-322.

. Oproblema sociológico das gerações. In: FORACCHI, Marialice; MANNHEIM, Karl. São Paulo: Editora Ática, 1982. (Coleção Grandes Cientistas Sociais, 25). p. 67-96.

MONTANDON, Cleopatre. Sociologia da infância: balanço dos trabalhos em língua inglesa. Cadernos de Pesquisa, São Paulo, n. 112, mar. 2001. p. 33-60.

NOBRE, J. C.; PEDRO, R. M. Reflexões sobre possibilidades metodológicas da teoria ator-rede. In: Cadernos UNIFOA, n. 14, dez. 2010. Disponível em: <www.foa.org.br/ cadernos/edicao/14/47.pdf>. Acesso em: 30 mar. 2013.

PROUT, Alan. The future of childhood: towards the interdisciplinar study of children. London, New York: Routledge Falmer, 2005. (The future of childhood series).

Reconsiderando a nova Sociologia da Infância. Cadernos de Pesquisa, São Paulo, v. 40, n. 141, p. 729-750, set./dez. 2010.

QVORTRUP, Jens. Nine theses about "childhood as a social phenomenon. In: QVORTRUP, Jens. (Ed.). Childhood as a social phenomenon: lessons from an international project. Eurosocial Report 47. Vienna: European Centre, 1993.

. Childhood matters: an introduction. In: QVORTRUP, Jens et al. (Org.). Childhood Matters. Social theory, practice and politics. Avebury: European Center of Viena, 1994. 
. Childhood Exclusion by Default. In: QVORTRUP, Jens. Working Paper 9. Child and Youth Culture. Odense University Printing Office, 1999. Disponível em: <http://static.sdu.dk/mediafiles/Files/Information_til/Studerende_ ved_SDU/Din_uddannelse/Kultur_og_formidling/WorkingPapers/09_ ChildhoodAndSocietalMacrostructures\%20pdf.pdf>. Acesso em: 30 mar. 2013.

Sociology of childhood: conceptual liberation of children. In: MOURITSEN, Fleming; QVORTRUP, Jens. Childhood and children's culture, 2002.

. Varieties of childhood. In: QVORTRUP, Jens. Studies in modern childhood. Palgrave: MacMillan, 2005a.

. 0 pequeno "s" e as perspectivas para os estudos da infância. In: CONFEREANCIA INTERNACIONAL CHILDHOODS. 29 jun./3 jul.. Anais. Oslo: University of Oslo, 2005b.

. Macroanálise da infância. In: CHRISTENSEN, Pia; JAMES, Allison (Org.). Investigação com crianças: perspectivas e práticas. Porto: Paula Frassinetti, 2005c. p. 73-96.

; CORSARO, William; HONIG, Michael-Sebastian. The palgrave handbook of childhood studies. London: PalgraveMacmillan, 2009a.

ROLNIK, Suely. Cartografia sentimental, transformações contemporâneas do desejo. São Paulo: Estação Liberdade, 1989.

TEBET, Gabriela G. de C. Isto não é uma criança! Teorias e métodos para o estudo de bebês nas distintas abordagens da sociologia da infância de língua inglesa. 2013. Tese (Doutorado em Educação)- Programa de Pós-Graduação em Educação da Universidade Federal de São Carlos, São Paulo, 2013.

VEYNE, Paul. Como se escreve a história; Foucault revoluciona a história. 4. ed. Brasília: Editora Universidade de Brasília, 1998.

. Foucault, o pensamento, a pessoa. Lisboa: Ed. Texto e Grafia, 2009.

VIRNO, Paolo. Multidão e princípio de individuação. Tradução de Leonardo R. Palma. In: Lugar Comum, n. 19, p. 27-40, s/d. Disponível em: <http://uninomade.net/wpcontent/files_mf113003120835Multid\%C3\%A30\%20e\%20princ\%C3\%ADpio\%20 de $\% 20$ individua $\%$ C3\%A7\%C3\%A30\%20-\%20Paolo\%20Virno.pdf>. Acesso em: 30 mar. 2013.

WOODHEAD, Martin; FAULKNER, Dorothy. Sujeitos, objetos ou participantes? Dilemas da investigação psicológica com crianças. In: CHRISTENSEN, Pia; JAMES, Allison (Org.). Investigação com crianças perspectivas e práticas. Porto: Paula Frassinetti, 2005. p. 13-25. 
Recebido em julho de 2013

Aprovado em novembro de 2013

Gabriela Guarnieri de Campos Tebet é doutora em Educação pela Universidade Federal de São Carlos e professora de Educação Infantil da Prefeitura Municipal de São Carlos e do curso de Especialização em Educação Infantil da mesma universidade. E-mail: gabrielagtebet@yahoo.com.br.

Anete Abramowicz é doutora em Educação e professora titular do Departamento de Teorias e Práticas Pedagógicas da Universidade Federal de São Carlos. Pesquisa produtividade 1D do CNPq. E-mail: anetabrađufscar.br. 